\title{
ANALISIS INFORMASI ANATOMI ANTARA SEKUENS T2WI FSE DAN PROTON DENSITY FAT SATURATION PADA PEMERIKSAAN MRI KNEE JOINTPOTONGAN SAGITAL (Studi pada Anterior Cruciate Ligament (ACL) dan Posterior Cruciate Ligament (PCL))
}

\section{ANALYSIS OF ANATOMICAL INFORMATION BETWEEN T2W1 FSE SEQUENCE AND PROTON DENSITY FAT SATURATION OF KNEE JOINTMRI EXAMINATION SAGITAL SLICE \\ (A Study on Anterior Cruciate Ligament (ACL) and Posterior Cruciate Ligament (PCL))}

\author{
Atina Izzah Kusumaningrum ${ }^{1)}$, Lydia Purna W.S.K ${ }^{2)}$, Gatot Murti Wibowo ${ }^{3}$ \\ 1) PKU Muhammadiyah Cepu Hospital \\ ${ }^{2)}$ Nasional Diponegoro Semarang Hospital \\ ${ }^{3)}$ Health Polytechnics of Semarang-Indonesia \\ e-mail: atinaizzah@gmail.com
}

\begin{abstract}
Background: There are clinical situations that radiology physicians need to assess Anterior Cruciate Ligament (ACL) and Posterior Cruciate Ligament (PCL) clearly with the two typical sequences (T2WI FSE sequence and Proton Density Fat Saturation). However, a slight difference in using the applied sequences will result different levels of image quality information. The aim of this study is to compare clinical manifest in anatomical information on the resulted images between T2WI FSE sequence and Proton Density Fat Saturation and to define the best sequence that fit to reveal ACL and PCL of the knee joint..

Methods: The research was an experimental quasy. 20 sagital slices of the knee jointMRI were acquired from 10 volunteers who underwent MRI examinations with the two methods (T2WI FSE and Proton Density Fat Saturation). 3 experienced radiology physicians blended in the image scoring when review ACL and PCL appearances on knee MRI images. Inter-observer suitability was checked with Kappa test. A nonparametric Wilcoxon analyses was the statistical tool to test the null hypothesis.

Results: The result showed a significant difference in anatomical information of ACL and PCL when T2WI FSE and Proton Density Fat Saturation sequences applied on the MRI of the knee jointsagital slices ( $\mathrm{p}$-value <0,05). The mean rank of T2WI FSE was better than Proton Density Fat Saturation which contributed to the value at 4,50. There was an increase in signals that lead to ACL and PCL appear to be more hyper-intens compared to sorrounding organs in general, except the border line of PCL. By this means, it was useful for evaluating the patient whose particularly with ACL post-grafting.

Conclusion: There was the difference in anatomical information between T2WI FSE sequence and Proton Density Fat Saturation on MRI knee jointwith sagital slices for ACL and PCL studies. T2WI FSE sequence was the best method for showing anatomical information of ACL and PCL, although a relative low signal still occured from border line of PCL.
\end{abstract}

Keywords: knee joint, T2WI FSE, Proton Density Fat Saturation, Anterior Cruciate Ligament (ACL) and Posterior Cruciate Ligament (PCL)

\section{PENDAHULUAN}

Anterior Cruciate Ligament (ACL) dan Posterior Cruciate Ligament (PCL) adalah salah satu ligamen yang berada pada lutut. Ligamen-ligamen tersebut adalah struktur putih penyambung jaringan yang mengikat tulang ke tulang dan menstabilisasi lutut. (Siowik, FRCS, 2009).

Berbagai patologis banyak terjadi di knee joint, salah satunya adalah trauma pada Anterior Cruciate Ligament (ACL) dan Posterior Cruciate Ligament (PCL). Menurut Allen (2016), cedera Posterior Cruciate Ligament (PCL) kurang umum daripada cedera Anterior Cruciate Ligament ( ACL ), dan PCL sering tidak dikenali. PCL adalah lebih luas permukaannya dan lebih kuat dari ACL dan memiliki kekuatan tarik 2000 Newton.

Menurut Westbrook (2008), protokol untuk menampilkan Anterior Cruciate Ligament (ACL) dan Posterior Cruciate Ligament (PCL) memerlukan 3 potongan yaitu sagital, coronal, dan axial. Untuk potongan sagital sekuens yang dipergunakan adalah coherent GRE T2*/ T2WI FSE/ Proton Density/ Proton Density Fat Saturation/ T2WI Fat Saturation.

Khoury NJ (2011) melakukan penelitian dengan tujuan menentukan akurasi dan kesepakatan pengamatan untuk menilai internal knee derangement dengan sagital sekuens Proton Density FSE Fat Sat dibandingkan dengan T1 SE, dual Proton Density, T2 FSE dan dengan anthroscopy. Dengan dasar penelitian diatas maka penulis ingin mengkaji lebih dalam tentang penggunaan sekuen T2WI FSE dan Proton Density Fat Sat untuk menampakkan ACL dan PCL.

Dalam kasus pemeriksaan MRI dengan berbagai kasus pada knee joint, pada potongan sagital sering dilakukan dengan pembobotan T2WI FSE atau Proton Density Fat Sat. 
Tujuan dari penelitian ini adalah untuk mengetahui perbedaan informasi anatomi antara sekuens T2WI FSE dengan sekuens Proton Density Fat Saturation pada pemeriksaan MRI knee joint potongan sagital studi pada Anterior Cruciate Ligament (ACL) dan Posterior Cruciate Ligament (PCL) dan untuk mengetahui sekuens yang lebih baik dan dapat dijadikan protokol rutin MRI knee joint untuk menilai Anterior Cruciate Ligament (ACL) dan Posterior Cruciate Ligament (PCL).

\section{METODE}

Jenis penelitian ini merupakan penelitian quasi experimental design with control. Bertujuan untuk mengetahui perbedaan informasi anatomi Anterior Cruciate Ligament (ACL) dan Posterior Cruciate Ligament (PCL) antara sekuens T2WI FSE dengan Proton Density Fat Saturation pada pemeriksaan MRI knee jointpotongan sagital.

10 orang sampel untuk dilakukan pemeriksaan MRI Knee joint dengan dua perlakuan pada satu orang sampel yaitu dengan memberikan dua sekuens T2WI FSE dan sekuens Proton Density Fat saturation.

Kriteria ekslusi pada penelitian ini adalah volunteer sehat dengan syarat yang tidak pernah mengalami trauma pada knee joint, tidak nyeri pada daerah knee joint, dan tidak ada pengobatan artritis atau steorid. Sedangkan kriteria inklusinya yaitu usia $<30$ tahun, berat badan $<60 \mathrm{~kg}$ atau IMT normal. Responden yang memberikan penilaian terhadap citra MRI knee joint adalah 3 (tiga) orang dokter spesialis radiologi.

Prosedur dalam penelitian ini dimulai dengan memberikan volunteer lembar inform consent tentang maksud dan tujuan penelitian serta diberi penjelasan tentang prosedur pemeriksaan, serta diyakinkan bahwa menelitian ini tidak membahayakan. Kemudian dilanjutkan dengan pembuatan citra MRI knee joint dengan parameter T2WI FSE dan sekuens Proton Density Fat saturation yang telah ditentukan. Setiap volunteer dilakukan scanning dengan dua kali metode yaitu T2WI FSE dan sekuens Proton Density Fat saturation. Kemudian citra hasil penelitian tersebut disimpan didalam CD dengan format DICOM tanpa ada keterangan identitas apapun, hanya diberikan kode serial citra. Penilaian citra MRI knee joint diberikan pada 3 orang dokter spesialis radiologi yang memiliki pengelaman di dalam MRI kurang lebih selama 5 tahun. Penilaian dilakukan terhadap informasi anatomi, meliputi tingkat intensitas daerah Anterior Cruciate Ligament (ACL) dan Posterior Cruciate Ligament (PCL), dan batas dengan struktur disekitarnya (border line). Pemberian nilai dilakukan dengan cara memberikan tanda check $(\sqrt{ })$ pada kuisioner yang telah disediakan. Kriteria penilaiannya adalah sebagai berikut : skor 4 berarti "sangat jelas", skor 3 berarti "jelas", skor 2 berarti "kurang jelas", dan skor 1 berarti "tidak jelas".

Data ditabulasi dalam excel lalu diolah dan diuji menggunakan program SPSS 16,0. Data yang didapatkan berupa data ordinal berpasangan, dan menggunakan dua kelompok variabel maka uji yang digunakan adalah wilcoxon untuk menilai ada tidaknya perbedaan antara dua variabel tersebut dengan tingkat kemaknaan 95\%. Untuk mengetahui sekuens mana yang lebih baik dalam menampakkan informasi anatomi ACL dan PCL yaitu dengan melihat nilai mean rank tertinggi yang merupakan suatu tanda sekuens tersebut optimal.

\section{HASIL}

Sampel penelitian terhadap 10 (sepuluh) sukarelawan sehat, berjenis kelamin laki-laki dan perempuan, rentang usia $<30$ tahun dengan berat badan $<60 \mathrm{Kg}$ dan nilai IMT normal, dengan distribusi karakteristik pasien dijelaskan dalam tabel dibawah ini :

Tabel 1. Distribusi Sample Berdasarkan Jenis Kelamin

\begin{tabular}{ccc}
\hline Jenis Kelamin & N (Jumlah) & Persentase (\%) \\
\hline Laki-laki & 3 & $30 \%$ \\
Perempuan & 7 & $70 \%$ \\
\hline Jumlah & 10 & $100 \%$ \\
\hline Tabel 2. Distribusi Sampel Berdasarkan Umur \\
\hline Umur & N (Jumlah) & Persentase (\%) \\
\hline $19-21$ & 1 & $10 \%$ \\
$22-24$ & 6 & $60 \%$ \\
$25-27$ & 2 & $20 \%$ \\
$28-30$ & 1 & $10 \%$ \\
\hline Jumlah & 10 & $100 \%$ \\
\hline
\end{tabular}

Tabel 3. Distribusi Sampel Berdasarkan Berat Badan

\begin{tabular}{rcc}
\hline Berat Badan & N (Jumlah) & Persentase (\%) \\
\hline $50-52$ & 2 & $20 \%$ \\
$53-55$ & 4 & $40 \%$ \\
$56-58$ & 2 & $20 \%$ \\
$59-61$ & 2 & $20 \%$ \\
\hline Jumlah & 10 & $100 \%$ \\
\hline
\end{tabular}

Informasi anatomi yang dinilai adalah tingkat intensitas ACL, border line ACL, tingkat intensitas PCL, dan border line PCL. Citra anatomi pemeriksaan MRI knee joint sekuens T2WI FSE dengan Proton Density (PD) Fat Saturation yang dinilai oleh responden sebanyak 20 citra, terdiri dari 10 citra T2WI FSE dan 10 citra Proton Density (PD) Fat Saturation.

Hasil citra MRI knee joint antara sekuens T2WI FSE dengan Proton Density (PD) Fat Saturation :

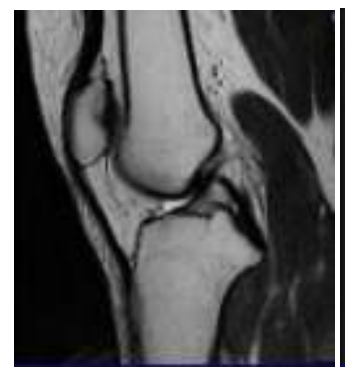

a

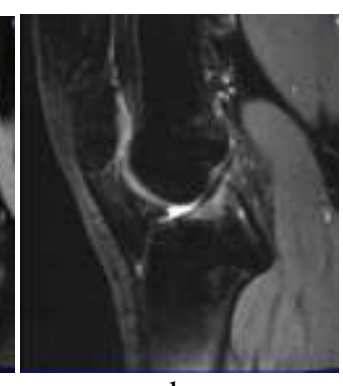

$\mathrm{b}$
Gambar 1. Irisan Sagital T2WI FSE (a) dan Proton Density Fat Saturation (b) 
Sebelum hasil penelitian dari masing-masing sekuen terhadap informasi anatomi dari tiga dokter spesialis radiologi sebagai responden penelitian dianalisis dengan uji wilcoxon, terlebih dahulu melakukan analisis uji statistik Cohen's Kappa untuk mengetahui tingkat kesepakatan atau tingkat obyektifitas dari penilaian ketiga responden terhadap penelitian tersebut. Hasil Kappa test adalah sebagai berikut :

Tabel 4. Kappa Test Terhadap Penilaian T2WI FSE Dan Proton Density Fat Saturation

\begin{tabular}{|c|c|c|c|c|c|}
\hline \multirow{3}{*}{ Sekuen } & \multirow{2}{*}{\multicolumn{3}{|c|}{$\begin{array}{l}\text { Tingkat Kesepakatan } \\
\text { Cohen's Kappa }\end{array}$}} & \multirow{3}{*}{$\begin{array}{l}\text { Rata- } \\
\text { rata }\end{array}$} & \multirow{3}{*}{$\begin{array}{l}\text { Keteranga } \\
\mathbf{n}\end{array}$} \\
\hline & & & & & \\
\hline & $\begin{array}{l}\mathbf{R} 1 * \mathbf{R} \\
\mathbf{2}\end{array}$ & $\begin{array}{l}\mathbf{R} 2 * \mathbf{R} \\
\mathbf{3}\end{array}$ & $\begin{array}{l}\mathbf{R} 2 * \\
\mathbf{R} 3\end{array}$ & & \\
\hline T2WI FSE & 0,696 & 0,650 & 0,550 & 0,632 & Baik \\
\hline $\begin{array}{l}\text { Proton } \\
\text { Density FS }\end{array}$ & 0,705 & 0,578 & 0,554 & 0,612 & Baik \\
\hline
\end{tabular}

Nilai tingkat kesepakatan paling tinggi ada pada responden 1 dengan responden 2 yaitu pada sekuens T2WI FSE 0,696 dan sekuens proton density Fat Saturation 0,705. Menurut Altman (1991), nilai koefisien kappa antara 0,61 hingga 0,80 menunjukkan tingkat kesepakatan baik, oleh karena itu hasil kappa dari responden 1 dengan responden 2 dikatakan memiliki kesepakatan yang baik.

Tabel 5. Hasil Uji Wilcoxon perbedaan informasi anatomi secara keseluruhan antara T2WI FSE dengan sekuens Proton Density Fat Saturation

\begin{tabular}{cc}
\hline Sekuen & $p$-value \\
\hline T2WI FSE & 0,005 \\
Proton Density Fat Saturation & \\
\hline
\end{tabular}

Tabel 6. Hasil Uji Wilcoxon perkriterian anatomi antara sekuens T2WI FSE dengan Proton Density Fat Saturation

\begin{tabular}{|c|c|}
\hline Informasi Citra & $p$-value \\
\hline $\begin{array}{l}\text { Intensitas ACL sekuens } \\
\text { T2WI FSE }\end{array}$ & \\
\hline $\begin{array}{llr}\text { Intensitas } & \text { ACL } & \text { sekuens } \\
\text { Proton } & \text { Density } & \text { Fat } \\
\text { Saturation } & & \end{array}$ & 0,046 \\
\hline $\begin{array}{l}\text { Border line ACL sekuens } \\
\text { T2WI FSE }\end{array}$ & \\
\hline $\begin{array}{l}\text { Border line ACL sekuens } \\
\text { Proton Density Fat }\end{array}$ & 0,034 \\
\hline $\begin{array}{l}\text { Saturation } \\
\text { Intensitas PCL sekuens } \\
\text { T2WI FSE }\end{array}$ & \\
\hline $\begin{array}{llr}\text { Intensitas } & \text { PCL } & \text { sekuens } \\
\text { Proton } & \text { Density } & \text { Fat } \\
\text { Saturation } & & \end{array}$ & 0,035 \\
\hline $\begin{array}{l}\text { Border line PCL sekuens } \\
\text { T2WI FSE }\end{array}$ & \\
\hline $\begin{array}{l}\text { Border line PCL sekuens } \\
\text { Proton Density } \\
\text { Saturation }\end{array}$ & 0,034 \\
\hline
\end{tabular}

Uji beda dilakukan pada keseluruan dengan membandingkan nilai total dari keseluruhan kriteria anatomi yang dinilai pada citra MRI knee joint sekuens T2WI FSE dengan sekuens Proton Density Fat Saturation potongan sagital

Berdasarkan hasil uji statistik non parametrik pada tabel 5 menunjukkan nilai signifikan $p$ value $=0.005$ atau $p<0.05$, artinya Ho ditolak dan Ha diterima, menunjukkan adanya perbedaan yang signifikan pada informasi anatomi antara sekuens T2WI FSE dengan Proton Density Fat Saturation pada pemeriksaan MRI knee joint potongan sagital.

Berdasarkan nilai mean rank pada uji wilcoxon untuk sekuens T2WI FSE adalah 4,50 sedangkan sekuens Proton Density Fat Saturation adalah 0,00. Hal ini menunjukkan bahwa sekuens T2WI FSE pada pemeriksaan MRI Knee joint menghasilkan informasi anatomi yang lebih baik daripada sekuens Proton Density Fat Saturation.

Pada tabel 6 merupakan hasil uji Wilcoxon untuk perkriteria anatomi. Uji beda untuk perkriteria anatomi dilakukan untuk mengetahui perbedaan antar kriteria yang dinilai.

Nilai intensitas ACL $p$ value $=0,046$, border line ACL $p$ value $=0,034$, Intensitas PCL $p$ value $=0,035$, dan border line PCL $p$ value $=0,034$. Hal ini menunjukkan bahwa ada perbedaan informasi anatomi pada kriteria anatomi intensitas ACL, border line ACL, intensitas PCL, dan border line PCL. Untuk menentukan mana yang lebih baik dalam menampakkan setiap kriteria anatomi dapat dilihat pada hasil mean rank pada tabel dibaah ini :

Tabel 7. Hasil Mean rank Uji Statistik Wilcoxon pada Informasi Anatomi antara sekuens T2WI FSE dengan sekuens Proton Density Fat Saturation

\begin{tabular}{ccc}
\hline Kriteria & Sekuen & $\begin{array}{c}\text { Mean } \\
\text { rank }\end{array}$ \\
\hline Intensitas ACL & Proton Density & 2,50 \\
& Fat Saturation \\
T2WI FSE & 4,25 \\
Border line ACL & Proton Density & 0,00 \\
& Fat Saturation & 3,00 \\
Intensitas PCL & T2WI FSE & 4,00 \\
& Proton Density & 4,57 \\
Bat Saturation & T2WI FSE & 4,50 \\
& Proton Density & 4,50 \\
\hline
\end{tabular}

Hasil mean rank uji wilcoxon pada tabel 7 menunjukan bahwa sekuens T2WI FSE memiliki nilai yang lebih tinggi pada seluruh kriteria anatomi kecuali untuk anatomi border line PCL. Kriteria anatomi border line antara sekuens T2WI FSE dan sekuens Proton Density Fat Saturation memiliki nilai mean rank yang sama yaitu 4,50 . Untuk nilai mean rank tertinggi pada sekuens T2WI FSE ada pada informasi anatomi intensitas PCL yaitu sebesar 4,57 dan nilai mean rank tertinggi pada sekuens Proton Density Fat Saturation ada pada anatomi border line PCL yaitu 4,50. 


\section{DISKUSI}

Berdasarkan hasil uji statistik non parametrik menunjukkan nilai signifikan $p$ value $=0.005$ atau $p<0.05$, artinya Ho ditolak dan Ha diterima, menunjukkan adanya perbedaan yang signifikan pada informasi anatomi antara sekuens T2WI FSE dengan Proton Density Fat Saturation pada pemeriksaan MRI knee joint potongan sagital. Namun hasil uji wilcoxon pada informasi citra per kriteria anatomi terdapat beberapa organ yang tidak berbeda secara signifikan yaitu pada anatomi intensitas ACL. Perbedaan ini disebabkan karena masing-masing sekuens mempunyai fungsi masingmasing serta memiliki kelebihan dan kekurangan. Parameter yang digunakan pada sekuens T2WI FSE adalah TR yang panjang ( > $2000 \mathrm{~ms}$ ) dan TE yang panjang (>60 ms). Dengan TR yang panjang maka akan memberikan kesempatan air untuk decay dan TE yang panjang akan dapat mendeteksi perbedaan sinyal antara air dan lemak. Sehingga dengan menggunakan sekuens T2WI FSE ACL dan PCL akan terlihat hypointense dan cairan akan lebih jelas. Hal ini dikarenakan struktur ACL dan PCL terdiri dari serat tendon yang mayoritas padat sehingga pada sekuens T2WI FSE akan tampak hypointense. Sedangkan untuk parameter Proton Density Fat Saturation menggunakan Long TR dan Short TE dan teknik Fat Saturation. Pada Proton Density parameter yang berpengaruh terhadap kualitas gambaran adalah nilai TR dan TE. Karena ditambahkan teknik Fat Saturation maka jaringan adiposa akan tampak gelap, lemak tampak gelap, cairan akan tampak terang, muscle akan tampak gelap dan tulang akan tampak gelap. Selain itu, teknik Fat Saturation tidak sensitif pada inhomogenitas magnet sehingga apabila struktur organ tersebut tidak homogen maka organ tersebut tidak akan tersupresi dengan baik sehingga pada gambaran anatomi ACL dan PCL tidak begitu terlihat jelas.

Hasil penilaian informasi anatomi yang lebih baik antara penggunaan sekuens T2WI FSE Dengan sekuens Proton Density Fat Saturation pada pemeriksaan MRI Knee joint potongan sagital. Jika dilihat dari hasil mean rank untuk keseluruhan anatomi pada pengujian Statistik Non Parametrik Wilcoxon didapatkan hasil bahwa sekuens T2WI FSE lebih baik dalam menampakkan informasi anatomi daripada sekuens Proton Density Fat Saturation.

Infromasi citra anatomi pada sekuens T2WI FSE dan Proton Density Fat Saturation tidak seluruhnya terdapat perbedaan. Pada informasi anatomi border line antara sekuens T2WI FSE dan sekuens Proton Density Fat Saturation memiliki nilai mean rank yang sama.

Sekuens T2WI FSE lebih baik karena dengan sekuens tersebut ACL dan PCL akan tampak ada peningkatan sinyal apabila terjadi patologi. Peningkatan sinyal pada T2WI FSE sangat dibutuhkan contohnya setelah operasi rekontruksi ligamen setelah itu pasti pasien akan diminta untuk kontrol dan ACL graft harus tampak sebagai struktur yang kencang dan hal yang harus dilakukan adalah butuh peningkatan sinyal yaitu dengan menggunakan sekuens T2WI FSE pada potongan sagital.

Sedangkan menurut Berquist (2013), Acute tears pada pembobotan T2 atau sekuens yang sensitif pada air akan menampakkan intensitas sinyal yang tinggi, sehingga akan mudah dikenali jika ada kelainan di ligamen.

Menurut George R, J. Dela, (2014), penggunaan sekuens PD Fat Saturation berguna untuk mengidentifikasi patologi dengan konten jaringan adiposa akan tampak gelap pada PD Fat Saturation ( misalnya lipoma ). Karena ditambahkan teknik Fat Saturation, proses patologis biasanya akan tampak cerah pada PD Fat Saturation.

Menurut Criffreda, L (2013), sekuens PD Fat Saturation sangat sensitif untuk mendeteksi bone contusions daripada PD FSE dan pembobotan T2.

\section{SIMPULAN}

Dari hasil pembahasan, terdapat beberapa hal yang dapat peneliti simpulkan. Yang pertama terdapat perbedaan informasi citra secara keseluruhan yang signifikan antara sekuens T2WI FSE dan Proton Density Fat Saturation dengan $P$-value 0,005 $(P<0,05)$ dengan confident level 95\%. Terdapat perbedaan informasi anatomi intensitas ACL $P=0,046$; border line ACL $P=0,034$; Intensitas PCL $P=0,035$; border line PCL $P=0,034$.

Kemudian nilai mean rank pada sekuens T2WI FSE lebih tinggi dibandingkan sekuens Proton Density Fat Saturation pada seluruh informasi citra kecuali anatomi border line PCL. Anatomi border line PCL memiliki nilai mean rank yang sama yaitu 4,50 sedangkan nilai mean rank tertinggi pada sekuens T2WI FSE ada pada informasi anatomi intensitas PCL yaitu sebesar 4,57 dan nilai mean rank tertinggi pada sekuens Proton Density Fat Saturation ada pada anatomi border line PCL yaitu 4,50. Secara umum sekuens T2WI FSE memiliki kemampuan yang lebih baik dari Proton Density Fat Saturation dalam menampakkan informasi citra.

\section{DAFTAR PUSTAKA}

Allen, Anton M. 2016. MRI for Anterior Cruciatum Ligamen injuries.Medscape.http://emedicine.medscape.com/article/400547overview\#a6 diakses 1 Maret 2016.

Baltazar, R, shankman S, Beltran J. 2009. Computed Tomography and Magnetic Resonance Imaging of Whole Body Vol 2 Fifth edition. Mosby Elsevier : Philadelphia.

Berquist, Thomas H, 2013. MRI OF THE Musculoskeletal System Sixth Edition. Wolters Kluwer Lippincott Williams \& Wilkins Philadelphia.

Bontrager, Kenneth L. 2014. Textbook of Radiographic Positioning and Related Anatomy. Missouri : Mosby, Inc.

Blink, Ever. 2004. MRI : Physics, www.radiologyphysics.bitica.com. Diakses pada tanggal 20 Februari 2016.

George R, J. Dela Cruz, R. Singh, dan Fran Han. 2014. MRI Of Knee. www.mrimaster.com. Diakses pada tanggal 17 Maret 2016.

Helms, Clyde A. 2009. Musculoskeletal MRI Edisi 2. Saunders Elsevier Philadelphia.

Hornak, JP. 2011. The Basic of MRI. www.cis.rit.edu. Diakses pada tanggal 20 Februari 2016

Isbagio, Harry. 1996. Telaah Pengaruh Jangka Panjang Densitas Massa Tulang Total yang Rendah terhadap Progresivitas Kerusakan Matriks Tulang Rawan Sendi pada Osteoarthritis Sendi Lutut http://www.digilib.ui.ac.id/opac/themes/libri2/detail.jsp?id=83517

Kahle, W dan Leonhardt Platzer W. 1997. Atlas Berwarna dan Buku Teks Anatomi Manusia Sistem Lokomotor Muskuloskletal dan Topografi Buku Kedokteran ECG : Jakarta. 
Kuperman, V. 2003. Magnetic Resonance Imaging Physical Principles and Application. Academic Press.

Kweon, Christopher, Evan S. Lederman, dan Anikar Chhabra. 2013. Anatomy and Biomechanics of the Cruciate Ligaments and Their Surgical Implications. Springer : German.

Lumonga, Vadim. 2004. Sendi Lutut. Medan : USU Digital Library. www.repository.usu.ac.id. Diakses pada tanggal 20 Februari 2016.

Maguire, J. 2009. Anterior Crutiate Ligament Pathology. http://emedicine. medscape.com/article/1252414, diakses 1 Maret 2016.

Moeller and Reif. 2000. Atlas of Sectional Anatomy, Computer Tomography and Magnetic Resonance Imaging. Thiem Stuttgart : New York.

Pearce, Evelyn C. 2009. Anatomi dan fisiologi untuk Paramedis. PT. Gramedia Pustaka Utama : Jakarta.

Price, Sylvia A dan Lorraine M. Wilson. 2005. Patofisiologi: Konsep Klinis Proses-Proses Penyakit Volume 2 Edisi 5. ECG Emergency Arcan Buku Kedokteran.

Sugiyono. 2007. Metode Penelitian Tingkatan Administrasi. Alfabeta : Bandung.

Tokuda O, Y Harada, G Shiraishi dkk. 2012. MRI of The Anatomical Structures of The Knee: The Proton Density-Weighted Fast Spin Echo Sequence vs The Proton Density Weighted Fast Recovery Fast Spin Echo Sequence. The British Journal of Radiologi. Diakses 1 Maret 2016.

Westbrook, Catherine. 2008. Handbook of MRI Technique. Blackwell Science Ltd : United Kingdom.

Westbrook, Catherine. 2002. MRI at a Glance. Blackwell Science Ltd : United Kingdom

Westbrook, C. and Kaunt, C. 2011. MRI in Practise. Blackwell Science Ltd United Kingdom.

Wheeless, Clifford R. 2015. Wheeless's Textbook Of Orthopaedis. Duke Orthopaedics. Diakses 25 Juli 2016.

Woodward, Peggy ang William, W. Arrison, 1997, MRI Optimization, a hand on approach. McGraw-Hill, Co : USA.

Wu, Jing, Ling-Quan Lu, Jian-Ping Gu, Xin-Dao Yin. 2012. The Application of Fat-Suppression MR Pulse Sequence in the Diagnosis of BoneJoint Disease. International Journal of Medical Physic. Diakses 1 Maret 2016. 